\title{
FORMAÇÃO DE PROFESSORES PARA A JUSTIÇA SOCIAL: UMA REVISÃO DE ESTUDOS EMPÍRICOS
}

\author{
HELANE DE FÁTIMA GOMES FERNANDES ${ }^{1}$ \\ ORCID: https://orcid.org/0000-0003-3406-6975
}

ANA ISABEL ANDRADE ${ }^{2}$

ORCID: https://orcid.org/0000-0002-3182-9351

\begin{abstract}
RESUMO: Este estudo apresenta os resultados de uma análise de artigos publicados em revistas da área da Educação que relatam experiências de formação de professores para a justiça social. O objetivo é o de compreender como as formações docentes para a justiça social podem ser realizadas, a partir da identificação dos pressupostos teóricos que as fundamentam, das estratégias utilizadas e dos resultados alcançados por elas. A metodologia utilizada foi a da revisão sistemática de 10 artigos baseados em estudos empíricos, publicados entre 2009 e 2017, disponíveis para acesso livre em revistas acadêmicas da área. Após a seleção dos artigos, estes foram sujeitos a uma análise de conteúdo, o que possibilitou compreender práticas e princípios de formação docente para a justiça social. Os resultados mostram que as formações de professores para a justiça social se fundamentam em pedagogias de resistência, de caráter social e transformativo, para além de implicarem uma reflexão sobre a diversidade em diferentes níveis, sobre a educação multicultural e sobre as especificidades dos contextos educativos, exigindo dos formandos grande senso crítico.
\end{abstract}

Palavras-chave: Formação de Professores, Justiça social, Pedagogia crítica.

\section{TRAINING OF TEACHERS FOR SOCIAL JUSTICE: A REVIEW OF EMPIRICAL STUDIES}

\begin{abstract}
This study presents the results of an analysis of articles published in magazines in the area of Education that report experiences of training teachers for social justice. The objective is to understand how the documented training for social justice can be carried out, based on the identification of the theoretical assumptions that support it, the analyzes used and the results achieved by them. One methodology used was the systematic review of 10 articles based on empirical studies, published between 2009 and 2017, available for free access in specialized journals. After selecting the articles, they were submitted to a content analysis, what enabled the understanding of practices and principles of teacher education for social justice. The results show how teacher training for social justice are based on pedagogies of resistance, social and transformative character, in addition to implying a reflection on different levels, on multicultural education and on the specificities of educational contexts, requiring trainees great critical sense.
\end{abstract}

\footnotetext{
${ }^{1}$ Professora Adjunto da Faculdade de Linguagem - CUNTINS da Universidade Federal do Pará. Belém, Pará (PA), Brasil. $<$ helane@ufpa.br>.

2 Professora Associada do Departamento de Educação e Psicologia da Universidade de Aveiro. Aveiro, Portugal. <aiandrade@ua.pt>.
} 
Keywords: Teacher Education, Social Justice, Critical pedagogy.

\section{FORMACIÓN DE PROFESORES PARA LA JUSTICIA SOCIAL: UNA REVISIÓN DE ESTUDIOS EMPÍRICOS}

RESÚMEN: Este estudio presenta los resultados de un análisis de artículos publicados en revistas de Educación que informan experiencias de capacitación de maestros para la justicia social. El objetivo es comprender cómo se puede llevar a cabo la capacitación documentada para la justicia social, basada en la identificación de los supuestos teóricos que la respaldan, los análisis utilizados y los resultados logrados por ellos. Una metodología utilizada fue la revisión sistemática de 10 artículos basados en estudios empíricos publicados entre 2009 y 2017, disponibles para el acceso gratuito en revistas cientificas de educación. Después de la selección de los artículos, fueron sometidos a un análisis de contenido, o lo que permitió la comprensión de las prácticas y principios de la formación del profesorado para la justicia social. Los resultados muestran que la formación del profesorado para la justicia social se basa en pedagogías de resistencia, de carácter social y transformador, además de implicar una reflexión en diferentes niveles, en la educación multicultural y en las especificidades de los contextos educativos, lo que exige a los alumnos un gran sentido crítico.

Palabras clave: Formación del Profesorado, Justicia Social, Pedagogía Crítica.

\section{INTRODUÇÃO}

A formação docente comprometida com a justiça social vem sendo defendida como a perspectiva mais adequada para a promoção de uma educação preocupada com a construção de uma sociedade mais justa. Recentemente, observamos, no mundo, a ascensão de movimentos de extrema direita, as ameaças à democracia e o aprofundamento das relações conflituosas no que se refere à relação entre sujeitos de diferentes classes sociais, culturas ou etnias. Em resposta a essa ascensão, observamos o crescimento de um grupo de profissionais que tem buscado desenvolver estratégias para trabalhar, de forma mais intencional e clara, os princípios da justiça social na formação docente.

Escritos de Freire (1997), Giroux (1992) e Sá-Chaves (2014) sobre a formação de professores em sua dimensão humana, assim como os de Cochran-Smith (2010), Zeichner (2016), Moreira e Zeichner (2014) e Diniz-Pereira e Zeichner (2008) sobre a Formação do Professor para a Justiça Social (FPJS), evidenciam que as dimensões humana e social são consideradas importantes por parte das instituições responsáveis pela formação docente. No entanto, quando essas dimensões são tratadas, ainda o são numa perspectiva pouco enfatizada e valorizada em relação à perspectiva da formação do especialista que domina técnicas e conhecimentos da sua área de atuação, principalmente, quando falamos da formação de professores em áreas específicas.

Formar professores sob a perspectiva social constitui, assim, nos dias de hoje, um desafio. Zeichner (2014, p. 145) cita alguns problemas que impedem o avanço na FPJS, destacando que, apesar de muitas experiências realizadas, ainda faltam a capacidade de fazer o que precisa ser feito e mais evidências ou provas de que tais experiências têm apresentado resultados de caráter prático e satisfatório. 
Diante desse problema, julgamos necessário identificar as práticas da FPJS, compreender como ocorrem e conhecer seus resultados.

O estudo que aqui desenvolvemos fez um levantamento de experiências em FPJS disponíveis em bases de dados científicas qualificadas. Objetivamos identificar, nessas experiências, as principais referências teóricas, as estratégias didáticas formativas utilizadas e os principais resultados alcançados. Com isso, ao compreender as experiências descritas no estudo, visamos melhorar a qualidade das formações oferecidas aos professores de língua portuguesa dentro dos princípios da justiça social (formação essa que vem sendo realizada por uma das autoras deste trabalho) e fortalecer as práticas existentes, incentivando outros pesquisadores a se envolverem na FPJS.

Por ser mais adequado aos nossos objetivos, optamos por proceder a uma análise sistemática, estratégia geralmente aplicada à análise de grande número de dados, sendo esse o objetivo inicial de nosso projeto investigativo. Porém, no nosso levantamento de dados, obedecendo a todos os critérios aplicados na busca, seleção, inclusão e exclusão de textos, obtivemos um número total de 10 artigos/estudos publicados em revistas da área da Educação.

Como a intenção deste estudo é aprofundar as questões metodológicas dentro do tema pesquisado e compreender melhor o processo de formação de professores com foco na promoção da justiça social, resolvemos seguir na revisão de literatura, mesmo com um número de 10 estudos, o que não julgamos ser um problema, pois a revisão feita, e aqui apresentada, faz parte de uma investigação maior, tendo já permitido uma melhor compreensão do nosso objeto de estudo. Os estudos selecionados foram realizados em diferentes áreas e níveis de formação docente, por isso não especificamos um único nível de formação neste trabalho, pois estamos desenvolvendo um outro estudo sobre FPJS, em uma área e um nível específicos.

Nas próximas linhas, apresentamos o desenvolvimento de nosso estudo, descrito em três seções. Na primeira seção, apresentamos algumas das referências que subsidiam as nossas investigações e que apoiam nossas discussões. Em seguida, na segunda seção, detalhamos a metodologia utilizada e os critérios que nos fizeram chegar aos 10 estudos em questão. E, por fim, na terceira seção, apresentamos os resultados da análise e a discussão, e seguimos para as considerações finais.

\section{FORMAÇÃO DE PROFESSORES SOB A PERSPECTIVA MAIS HUMANA}

A formação docente pode seguir dois caminhos que tendem a ser tratados como perspectivas opostas. Um dos caminhos é aquele que está muito mais preocupado com a formação do especialista, o que domina e articula técnicas e competências no ensino, traduzindo-se numa concepção tecnicista que visa a formação do profissional, do "professor suficientemente bom", detentor de conhecimentos de um domínio específico, eficiente e capaz de apresentar resultados. Essa perspectiva reduz, muitas vezes, a educação aos interesses de mercado e à reprodução das relações de classe (PARESKEVA et al., 2005). 
Conforme Paulo Freire (1997), não é possível fazer uma reflexão sobre educação sem refletir sobre o próprio homem, ou seja, ao pensar sobre nós mesmos, podemos encontrar algo que possa constituir o núcleo fundamental do processo de educação. Esse é o caminho alternativo que tem como preocupação não só a formação profissional mas também a formação humana e democrática do sujeito docente. A formação humana (libertária) tem foco na formação pessoal e na profissional, é sensível do ponto de vista cultural e comprometida com o desenvolvimento da capacidade crítico-reflexiva, além disso é pertinente ao contexto, preocupa-se com a manutenção da democracia e da liberdade e com a emancipação em direção à justiça social. Nessa perspectiva, reconfigura-se a função do professor, o qual deixa de ser entendido como um simples executor do currículo e passa a ser encarado como um intelectual capaz de transformar o mundo. Sobre isso, Giroux (1997, p. 71) diz que:

\begin{abstract}
O intelectual transformativo é uma categoria que sugere que os professores enquanto intelectuais podem emergir de vários grupos e trabalhar com vários grupos, além da classe trabalhadora, incluindo-a. Grupos esses que propugnem as tradições emancipatórias e as culturais dentro e fora de esferas públicas alternativas [...]. É central para a categoria de intelectual transformativo a tarefa de tornar o pedagógico mais político, e o político mais pedagógico.
\end{abstract}

Sá-Chaves (2014, p. 13) fala dos novos desafios à formação de professores e da procura por "melhores soluções para os desafios que as sociedades contemporâneas colocam aos cidadãos, aos professores e à instituição escolar". Segundo a autora, os desafios com os quais, atualmente, o professor se confronta não passam exclusivamente pela construção de saberes, que correspondem aos conteúdos específicos a transmitir, mas também pela sua formação, sob uma perspectiva "pessoal, profissional e humana” (SÁ-CHAVES, 2014, p. 14). Reivindica-se, assim, uma formação docente com uma visão de que as pessoas, no processo educativo, possuem uma inscrição social e cultural no quadro dos direitos e deveres de exercício pleno da cidadania e do seu desenvolvimento humano.

Ao percorrer o caminho alternativo, encontramos algumas abordagens que se somam à perspectiva humana e libertária de formação, como a formação de professorespara a justiça social.

\title{
Formação de professores para a justiça social
}

Cochran-Smith (2010), Cochran-Smith et al. (2016, 2018), Diniz-Pereira e Zeichner (2008), Zeichner (2009, 2016), Moreira e Zeichner (2014) e Zeichner e Diniz-Pereira (2005), dentre outros autores, tratam a Formação de Professores para a Justiça Social como sendo uma abordagem com o seguinte objetivo:

Preparar professores a fim de contribuir para uma diminuição das desigualdades existentes entre as crianças das classes baixa, média e alta nos sistemas de escola pública de todo o mundo e das injustiças que existem nas sociedades, fora dos sistemas de ensino: em relação ao acesso à moradia, alimentação, saúde, transporte, ao trabalho digno que pague um salário justo (DINIZPEREIRA; ZEICHNER, 2008, p. 7). 
Essa abordagem é contrária à noção de formação do "professor suficientemente bom" apregoada por muitas políticas mundiais para a educação e formação de professores, sujeitas às leis de mercado (PARESKEVA et al., 2005; GIROUX; MCLAREN, 2011). Também conhecida como sociorreconstrucionista, multicultural, antirracista e inclusiva, a abordagem que elege a justiça social como foco não é simplesmente uma prática de reconhecimento e valorização da diversidade, mas, sim, uma formação capaz de levar professores, dentro e fora da sala de aula, a lutarem pela transformação da vida das pessoas, combatendo opressões e contribuindo para a redução das desigualdades existentes.

Uma educação para a justiça social está relacionada à justiça na e através da educação. $O$ acesso igualitário à educação significa a oportunidade de ir à escola e de lutar contra as desigualdades sociais, e, através do trabalho educativo e pedagógico, significa ainda superar as desigualdades sociais (BOLIVAR, 2012).

Zeichner (2016) mostra, por exemplo, que os currículos de formação de professores dos Estados Unidos da América (EUA) são deficientes para o sistema público de ensino, pois, apesar de aclamarem o enfoque na justiça social, são do tipo fast tracks (vias rápidas), isto é, constituem protocolos de formação para fácil e rápida conclusão, em que:

\footnotetext{
Os professores completam a maioria dos seus requisitos para certificação de professores oficiais, depois de algumas semanas de pré-formação, e muitos deles se concentram muito restritivamente sobre os aspectos técnicos de ensino e sucesso em testes padronizados de estudantes e ignoram outros aspectos do ensino e trabalho profissional como professores, sobre como exercer a avaliação na sala de aula e adaptar o seu ensino-aprendizagem em resposta à evolução das necessidades de seus estudantes. (ZEICHNER, 2016, p. 151).
}

A crítica do autor é a de que, na realidade, não há nenhuma abordagem prática nesses programas formativos voltada para a promoção da justiça social. A proposta alternativa a esses programas seria uma formação mais próxima dos valores de uma educação democrática para a justiça social e a equidade. Para tanto, é preciso que essa formação siga três passos: seja culturalmente sensível; permita a colaboração democrática e igualitária nos programas de formação, nos quais os conhecimentos e problemas da escola e das comunidades sejam incluídos; e contemple os valores e o compromisso com a justiça social e a democracia.

Essa perspectiva, na qual a comunidade participa na formação de professores, tem diferentes reflexos. Além da valorização dos conhecimentos, das variedades linguísticas e das práticas, nessa perspectiva, revelam-se os problemas do cotidiano enfrentados pelas comunidades e a busca por alternativas para superá-los.

Cochran-Smith (2010) preocupou-se em apresentar bases para a construção de uma teoria sobre a FPJS. Em primeiro lugar, a autora defende que é importante explicitar os objetivos finais da EPJS e considerar suas relações com as concepções de justiça existentes. Em segundo lugar, é necessário que 
se caracterize a atividade de ensino, a natureza do seu trabalho, os conhecimentos, as estratégias e os valores que sustentam o esforço dos professores pela justiça social. E, por fim, é importante que a EPJS se concentre em como os professores aprendem a ensinar pela justiça, nas estruturas que apoiam seu aprendizado ao longo do tempo e nos resultados dentro dos programas de formação, com objetivos claros de justiça social. A autora diz ainda que muitos estudiosos da formação docente discutem, em profundidade, a natureza pedagógica e prática da formação de professores para a justiça e que vale a pena estudá-la.

Portanto, na linha do que é apontado por Cochran-Smith (2010) e Zeichner (2014), sobre aprofundar estudos sobre a natureza pedagógica da FPJS e sobre a necessidade de se mostrar mais evidências ou provas de que as experiências em FPJS têm apresentado resultados de caráter prático e satisfatório, buscamos conhecer melhor o trabalho que vem sendo realizado por diferentes estudiosos, em diferentes cantos do mundo.

Ressaltamos que divulgar essas experiências demonstra o compromisso com o fortalecimento das ações em direção a uma educação promotora da justiça social. A seguir, apresentamos o passo a passo da construção do nosso estudo, o qual buscou conhecer essas experiências, bem como explicitamos os critérios que nos permitiram chegar aos estudos aqui analisados.

\section{O MÉTODO}

O mapeamento das experiências em FPJS é uma demanda incluída num projeto investigativo maior sobre o tema, que ambiciona saber como essas experiências têm ocorrido. Para isso, elegemos três questões principais a serem exploradas:

- Que referências teóricas têm subsidiado os estudos?

- Quais as estratégias metodológicas empregadas?

- Quais os seus principais resultados?

Com as questões definidas, de forma geral, objetivamos compreender como as formações para a justiça social podem ser realizadas, identificando os pressupostos teóricos que as fundamentam, as estratégias utilizadas e os resultados alcançados. Conhecer e compreender as experiências desenvolvidas por diferentes estudiosos e em diferentes contextos pode nos ajudar a compor novas experiências, adaptar estratégias e, de forma colaborativa, promover novas iniciativas em FPJS.

Relacionando questões e objetivos, julgamos que a melhor forma para conduzir este estudo seria realizar uma revisão sistemática de literatura sobre a temática em foco. Dentre todas as possibilidades, compreendemos que realizar um estudo de revisão seria o mais adequado, uma vez que se trata de uma estratégia metodológica que nos possibilita levantar e reunir estudos, avaliá-los criticamente e produzir uma síntese dos resultados de estudos primários sobre o tema (COOK; MULROW; HAYNES, 1997). 
Sobre o método da revisão de literatura, Sampaio e Mancini (2007, p. 84) dizem que "é importante destacar que esse é um tipo de estudo retrospectivo e secundário, isto é, a revisão é usualmente desenhada e conduzida após a publicação de muitos estudos experimentais sobre um tema", e que é muito importante a qualidade da fonte primária. Diante disso, passamos a pensar naquilo que julgamos ser fundamental para a nossa investigação: os critérios de seleção do corpus com garantia de qualidade, assim como a identificação de quais deles atenderiam ao problema posto por Zeichner (2014), sobre a falta de estudos que apresentem resultados efetivos sobre a FPJS.

Para a definição de critérios que garantissem qualidade na seleção do corpus final, passamos por três fases: definição das palavras-chave de busca/entrada, definição dos critérios de inclusão/exclusão e construção da grelha de análise.

A primeira fase constituiu-se da busca das palavras-chave "experiências+formação de professores+justiça social”, "práticas+formação docente+transformação social”, em diferentes línguas e em diferentes bases de dados científicas eletrônicas. As bases consultadas foram: Education Resources Information Center (ERIC); Scopus; Web of Science; Scientific Electronic Library Online - SciELO - Brasil; Sistema de Información Científica Redalyc - Red de Revistas Científicas de América Latina y el Caribe, España y PortugalMéxico; Biblioteca do Conhecimento Online (b-on) - Portugal; e Google scholar.

$\mathrm{Na}$ segunda fase, levamos em consideração os seguintes critérios de inclusão e exclusão: presença das palavras-chave de entrada/busca; pertinência dos dados face aos objetivos do estudo; disponibilidade dos textos em versão integral e de acesso livre; data de publicação nos últimos 10 anos (de 2008 a 2018); disponibilidade dos textos em base de dados qualificada; e divulgação em revistas/periódicos da área de educação. Com esses critérios, constituímos o primeiro conjunto de dados, que somou um total de 64 artigos. No entanto, a leitura dos abstracts mostrou que apenas 41 desses artigos atendiam aos objetivos da nossa investigação.

Seguindo para a terceira fase, a da seleção do corpus, levamos em consideração outro critério, qual seja, os estudos/textos deveriam apresentar a descrição clara e objetiva do trabalho didáticopedagógico, além de sua metodologia e dos resultados obtidos. Essa fase foi longa e trabalhosa, exigindo retornos contínuos às bases de dados ao longo de um ano, processo caracterizado por inclusões e exclusões, até o momento de fechamento para a escrita do presente texto. Por fim, através da combinação de todos esses critérios, chegamos a um conjunto de 10 artigos (Quadro 1), os quais nos parecem representar a realidade a que pretendíamos aceder. O Quadro 1, com a organização das referências completas dos estudos analisados, foi elaborado com apoio do software Mendeley. 
Quadro - 1: O corpus da pesquisa

\begin{tabular}{|c|c|}
\hline ORDEM & REFERENNCIA COMPLETA \\
\hline$[1]$ & $\begin{array}{l}\text { AJAYI, L. Preservice Teachers' Perspectives on Their Preparation for Social Justice } \\
\text { Teaching. The Educational Forum, v. 81, n. 1, p. 52-67, 2017. Disponível em: } \\
\text { https://doi.org/10.1080/00131725.2016.1242677. Acesso em: } 20 \text { mar. } 2018 .\end{array}$ \\
\hline [2] & $\begin{array}{l}\text { BORRERO, N. Preparing New Teachers for Urban Teaching: Creating a Community } \\
\text { Dedicated to Social Justice. Multicultural Perspectives, v. 11, n. 4, p. 221-226, dec. } 2009 . \\
\text { Disponível em: ttps://doi.org/10.1080/15210960903445723. Acesso em: } 20 \text { mar. } 2018 .\end{array}$ \\
\hline [3] & $\begin{array}{l}\text { BOYLAN, M.; WOOLSEY, I. Teacher education for social justice: Mapping identity spaces. } \\
\text { Teaching and Teacher Education, v. 46, p. 62-71, feb. 2015. Disponível em: } \\
\text { https://doi.org/10.1016/j.tate.2014.10.007. Acesso em: } 20 \text { mar. } 2018 .\end{array}$ \\
\hline [4] & $\begin{array}{l}\text { CONVERTINO, C. Beyond Ethnic Tidbits: Toward a Critical and Dialogical Model in } \\
\text { Multicultural Social Justice Teacher Preparation. International Journal of Multicultural Education, } \\
\text { v. } 18, \text { n. } 2 \text {, p. } 125-142,2016 .\end{array}$ \\
\hline [5] & $\begin{array}{l}\text { FONTOURA, H. A. da. Formação de Professores para a Justiça Social: uma reflexão sobre } \\
\text { a docência na Residência Pedagógica. RIAEE - Revista Ibero-Americana de Estudos Em } \\
\text { Educação, v. } 12 \text {, n. 1, p. 120-133, } 2017 \text {. }\end{array}$ \\
\hline [6] & $\begin{array}{l}\text { GIBSON, K..; PARKS, M. W. Toward Social Justice Literature to Promote Multiple } \\
\text { Perspectives. Multicultural Education, v. 21, n. 2, p. 41-50, Winter } 2014 .\end{array}$ \\
\hline [7] & $\begin{array}{l}\text { HENNING, N. We make the road by walking together: New teachers and the collaborative } \\
\text { and context-specific appropriation of shared social justice-oriented practices and concepts. } \\
\text { Teaching and Teacher Education, v. 36, p. 121-131, nov. 2013. Disponível em: } \\
\text { https:// doi.org/10.1016/j.tate.2013.07.014, Acesso em: } 26 \text { de março de } 2018 \text {. }\end{array}$ \\
\hline [8] & $\begin{array}{l}\text { MONTERO, L. G. B. Formación de nuevos docentes y educación continua para docentes } \\
\text { en servicio: su aporte a la justicia social. Letras 57, n. 1, p. 179-194, 2015. (ISSN 1409-424X; } \\
\text { EISSN 2215-4094). }\end{array}$ \\
\hline [9] & $\begin{array}{l}\text { STORMS, S. B. Preparing Teachers for Social Justice Advocacy Am I Walking My Talk? } \\
\text { Multicultural Education, v. 20, n. 2, p. 33-39, 2013. Disponível em: } \\
\text { http:/ / files.eric.ed.gov/ fulltext/EJ1015111.pdf. Acesso em: } 4 \text { nov. } 2018 .\end{array}$ \\
\hline$[10]$ & $\begin{array}{l}\text { TINKLER, B.; HANNAH, L.; MILLER, E.; TINKLER, A. The impact of a social justice } \\
\text { service-learning field experience in a social foundation course. Critical Questions in Education, } \\
\text { v. } 6, \text { n. } 1 \text {, p. } 16-29,2015 \text {. }\end{array}$ \\
\hline
\end{tabular}

Fonte: Elaboração nossa.

Além da aplicação desses critérios, os dados (textos identificados) foram avaliados de acordo com a classificação das revistas e periódicos em que foram publicados. Verificamos o H Index dos periódicos no site do SCImago Journal \& Country Rankque, um portal ligado ao banco de dados da Scopus ( (Elsevier B.V.), além da classificação Qualis-Periódicos (Quadro 2).

Quadro - 2: Classificação das revistas e periódicos em que os estudos foram divulgados

\begin{tabular}{|l|l|l|}
\hline \multicolumn{1}{|c|}{ REVISTA } & \multicolumn{1}{|c|}{ FATOR DE } & \multicolumn{1}{c|}{ PAÍS } \\
\hline International Journal of Research and & IMPACTO/QUALIS/HINDEX & \\
Studies Teaching and Teacher & Rualis A1 & Reino Unido \\
Education & H Index 93 & \\
(https://www.journals.elsevier.co & & \\
\hline
\end{tabular}




\begin{tabular}{|c|c|c|}
\hline REVISTA & $\begin{array}{c}\text { FATOR DE } \\
\text { IMPACTO/QUALIS/HINDEX }\end{array}$ & PAÍS \\
\hline \multicolumn{3}{|l|}{$\begin{array}{l}\mathrm{m} / \text { teaching-and-teacher- } \\
\text { education/) }\end{array}$} \\
\hline $\begin{array}{l}\text { RIAEE - Revista Ibero- } \\
\text { Americana de Estudos em } \\
\text { Educação } \\
\text { (http://seer.fclar.unesp.br/iberoa } \\
\text { mericana/index) }\end{array}$ & Qualis A2 (2016) & $\begin{array}{l}\text { Universidade de Alcalá de } \\
\text { Henares (UAH), Espanha, e a } \\
\text { Faculdade de Ciências e Letras } \\
\text { (FCL) da UNESP, de } \\
\text { Araraquara, São Paulo, Brasil }\end{array}$ \\
\hline Educational Forum & $H$ index 20 & Reino Unido \\
\hline $\begin{array}{l}\text { International Journal of Multicultural } \\
\text { Education }\end{array}$ & Hindex 9 & Estados Unidos \\
\hline Multicultural Education & $H$ index 13 & Estados Unidos \\
\hline $\begin{array}{l}\text { Journal of Research in Special } \\
\text { Educational Needs }\end{array}$ & $H$ index 20 & Reino Unido \\
\hline Multicultural Perspectives & $H$ index 9 & Estados Unidos \\
\hline
\end{tabular}

Fonte: Elaboração nossa.

Constituído o corpus, passamos para as informações sobre a análise, a qual contou com a elaboração e validação por especialistas de duas grelhas de análise, a aplicação da técnica de análise de conteúdo e a elaboração de quadros para melhor visualização dos resultados.

Para a análise dos dados, passamos por duas etapas, realizadas com a técnica de análise de conteúdo e com apoio de duas grelhas de análise (Grelhas 1 e 2) e do programa Excel. A primeira etapa foi baseada na observação dos aspectos técnicos e metodológicos dos estudos, e a segunda etapa fundamentou-se na observação de conteúdos, referências, abordagem didática e conclusões dos estudos. A elaboração das grelhas de análise ocorreu junto a equipes de trabalho, com diferentes pesquisadores da área da Educação ${ }^{3}$, e contou, portanto, com discussões junto a especialistas, os quais acompanharam todo o processo e validaram o instrumento.

Quadro - 3: Grelha de análise

\begin{tabular}{|l|l|}
\hline \multicolumn{1}{|c|}{ CATEGORIAS } & \multicolumn{1}{c|}{ DESCRIÇÃo } \\
\hline $\begin{array}{l}\text { 1. Problema/objeto/questão(ões) e objetivos da } \\
\text { investigação }\end{array}$ & $\begin{array}{l}\text { - Descrever quais são e avaliar sua clareza e } \\
\text { adequação }\end{array}$ \\
\hline $\begin{array}{l}\text { 2. Paradigma/natureza da investigação/tipo de } \\
\text { estudo }\end{array}$ & $\begin{array}{l}\text { - Especificar (quando indicados) e analisar sua } \\
\text { pertinência, atendendo aos aspetos do primeiro item }\end{array}$ \\
\hline $\begin{array}{l}\text { 3. Plano/método/design da investigação } \\
\text { 4. Participantes/amostra }\end{array}$ & $\begin{array}{l}\text { - Explicitar (se referido) e analisar sua adequação face } \\
\text { aos itens anteriores }\end{array}$ \\
\hline
\end{tabular}

\footnotetext{
${ }^{3}$ No âmbito do Programa de Doutoramento em Educação, da Universidade de Aveiro - Portugal.
} 


\begin{tabular}{|c|c|}
\hline CATEGORIAS & DESCRIÇÃO \\
\hline 5. Contexto (se aplicável) & - Descrever para inferir se as opções são adequadas \\
\hline $\begin{array}{l}\text { 6. Técnicas e Instrumentos de recolha de dados } \\
\text { (incluindo validação dos instrumentos) }\end{array}$ & $\begin{array}{l}\text { - Descrever e analisar se possibilitaram recolher } \\
\text { informação relevante e se foram acautelados } \\
\text { procedimentos de validação dos instrumentos - } \\
\text { qualidade dos dados }\end{array}$ \\
\hline 7. Técnicas de Tratamento/Análise dos Dados & $\begin{array}{l}\text { - Descrever e analisar se permitem testar as } \\
\text { hipóteses/dar resposta às questões de investigação e } \\
\text { se os resultados são fiáveis e válidos ou confiáveis e } \\
\text { transferíveis }\end{array}$ \\
\hline 8. Software de análise (se aplicável) & - Descrever e analisar sua pertinência \\
\hline 9. Limitações Metodológicas & $\begin{array}{l}\text { - Se não forem explicitadas, inferir tendo em conta a } \\
\text { literatura da especialidade }\end{array}$ \\
\hline 10. Referências & $\begin{array}{l}\text { - Analisar se são citados autores de referência ou } \\
\text { outros estudos que tenham servido de suporte } \\
\text { adequadamente }\end{array}$ \\
\hline 11. Outros comentários & $\begin{array}{l}\text { - Indicar a pertinência do estudo para o } \\
\text { aprofundamento das opções metodológicas do } \\
\text { projeto individual de investigação em curso }\end{array}$ \\
\hline
\end{tabular}

Fonte: Elaboração nossa.

Quadro - 4: Grelha de análise da etapa 2

\begin{tabular}{|l|l|}
\hline \multicolumn{1}{|c|}{ CATEGORIAS } & \multicolumn{1}{c|}{ DESCRIÇÃO } \\
\hline 1. Principais referências teóricas/temáticas & $\begin{array}{l}\text { - Identificar as principais referências teóricas e os temas } \\
\text { que apoiaram os estudos }\end{array}$ \\
\hline 2. Abordagem prática & - Identificar o trabalho didático desenvolvido \\
\hline 3. Resultados & - Identificar resultados e principais conclusões \\
\hline
\end{tabular}

Fonte: Elaboração nossa.

\section{RESULTADOS E DISCUSSÃO}

Como afirma Zeichner (2014), são necessárias mais evidências ou provas de que as experiências tenham apresentado bons resultados, e, para isso, julgamos importante observar as opções metodológicas, o tipo de estudo e as estratégias utilizadas pelos pesquisadores, para coletar informações sobre o processo de formação de professores.

Observamos que os estudos dão importância em identificar o paradigma, a natureza e os tipos de estudos que apoiaram suas investigações. No paradigma sociocrítico, autoincluem-se os estudos de Storms (2013) e Convertino (2016); no paradigma interpretativo, estão os estudos de Borrero (2009), 
Henning (2013), Gibson e Parks (2014), Tinkler, Hannah, Miller e Tinkler (2015), Boylan e Woolsey (2015), Fontoura (2017), Ajayi (2017) e Montero (2015). Quanto à natureza, todos os estudos enquadramse como qualitativos. E os tipos de estudos mais empregados foram o Estudo de caso, a Investigação participante e a Investigação-ação.

Quadro - 5: Tipo de estudo

\begin{tabular}{|l|l|}
\hline \multicolumn{1}{|c|}{ TIPO DE ESTUDO } & \multicolumn{1}{c|}{ REFERÊNCIA } \\
\hline Estudo de caso & Montero (2015) e Ajayi (2017) \\
\hline Investigação-ação & Storms (2013) \\
\hline Investigação participante & Borrero (2009) e Fontoura (2017) \\
\hline Múltiplos & $\begin{array}{l}\text { Boylan e Woolsey (2015) - Investigação participante, Estudo de caso } \\
\text { Henning (2013) - Estudo de caso, investigação participante e etnográfica } \\
\text { Tinkler, Hannah, Miller e Tinkler (2015) e Gibson e Parks (2014) - } \\
\text { investigação-ação e etnografia } \\
\text { Convertino (2016) - Investigação-ação e investigação participativa }\end{array}$ \\
\hline
\end{tabular}

Fonte: Elaboração nossa.

É interessante notar que todos os estudos optaram pela interação entre as técnicas e os instrumentos de recolha de dados, dentre as mais utilizadas, estão: o inquérito por entrevista e o questionário ao longo do processo, alguns estudos realizaram entrevistas e aplicaram questionários no início e no fim da formação; a observação; a coleta de artefatos, como planos de curso e planos de aulas; e as composições e reflexões escritas feitas pelos alunos, ao longo do curso de formação.

Os autores dos estudo, que também são os professores formadores nos cursos de formação, tiveram muita preocupação em refletir, posteriormente, sobre o próprio processo formativo. Além disso, preocuparam-se em constituir dados a partir de diferentes fontes, para obter mais evidências sobre os resultados e o impacto das formações. A interação entre os instrumentos de coleta de dados implica uma triangulação dos dados para a análise, uma das preocupações de Tinkler, Hannah, Miller e Tinkler (2015). Quanto à análise, alguns dos estudos também optaram pela interação entre diferentes técnicas.

Quadro - 6: Realização da análise

\begin{tabular}{|l|l|}
\hline \multicolumn{1}{|c|}{ ESTUDO } & \multicolumn{1}{|c|}{ TRATAMENTO E TÉCNICA DE ANÁLISE } \\
\hline Ajayi (2017) & O método analítico e interpretativo \\
\hline Borrero (2009) & Interpretação livre \\
\hline Boylan e Woolsey (2015) & $\begin{array}{l}\text { Análise temática no software Nvivo 8, a partir de codificação } \\
\text { indutiva para temas e interpretações emergentes }\end{array}$ \\
\hline
\end{tabular}




\begin{tabular}{|l|l|}
\hline \multicolumn{1}{|c|}{ ESTUDO } & \multicolumn{1}{|c|}{ TRATAMENTO E TÉCNICA DE ANÁLISE } \\
\hline Convertino (2016) & $\begin{array}{l}\text { Análise interpretativa a partir de codificação aberta e focada, para } \\
\text { desenvolver códigos descritivos }\end{array}$ \\
\hline Fontoura (2017) & Interpretação livre \\
\hline Gibson e Parks (2014) & Análise de conteúdo \\
\hline Henning (2013) & Memorando analíticos e comparação de eventos \\
\hline Montero (2015) & Interpretação livre \\
\hline Storms (2013) & $\begin{array}{l}\text { Análise de abordagem teórica fundamentada, memorandos } \\
\text { analíticos, codificação aberta e comparação }\end{array}$ \\
\hline Tinkler, Hannah, Miller e Tinkler (2015) & Análise de conteúdo a partir de codificação aberta \\
\hline
\end{tabular}

Fonte: Elaboração nossa.

De forma geral, esses estudos chamam atenção pelo rigor metodológico, o qual não foi percebido em outros estudos que, por esse motivo, não foram incluídos nesta análise, pois não deixaram evidente como os resultados foram alcançados. Como falamos anteriormente, além desses aspectos que julgamos muito importantes para a realização de estudos futuros, nossa análise explorou elementos que definimos como centrais de nosso levantamento: o contexto e os sujeitos; o quadro teórico-temático que apoiou os estudos; e as abordagens pedagógicas utilizadas, os principais resultados e as conclusões.

\section{O contexto e os sujeitos}

Os estudos analisados foram realizados no âmbito dos cursos de formação inicial e continuada de professores em diferentes áreas: Matemática, Ciências Sociais e Educação básica. Os cursos e os estudos ocorreram no âmbito da formação de professores, em instituições formais de ensino superior, e os autores são professores que, na oportunidade de suas aulas e cursos nas universidades, abordam a formação para a justiça social.

Além disso, são esses estudos produzidos também no âmbito das investigações científicas dos autores, portanto apresentam maiores informações do seu componente metodológico e controle do processo e mais evidências dos resultados, como referido anteriormente. Ainda assim, detectamos também que tais estudos são ações de iniciativa própria dos professores formadores e não decorrem de uma ação conjunta dentro das instituições de ensino e formação. Essa constatação leva-nos a pensar que isso implica em duas coisas: na própria aceitação da abordagem, uma vez que, mesmo sendo aclamada socialmente, há alguns estudos que relatam momentos de resistência; e na necessidade de construção de um discurso mais fortalecido em prol da justiça social, que não resulte apenas de iniciativas isoladas, 
sendo importante que as instituições formadoras também assumam, no seu discurso, a formação para a justiça social.

O número de sujeitos envolvido nos estudos é variado, sendo que alguns optam por apresentar todo o universo estudado ou apenas casos específicos, ou seja, o curso pode ter sido realizado com uma turma de 35 alunos, mas apenas os casos de 4 ou 6 sujeitos são apresentados.

Quadro - 7: Contextos e sujeito

\begin{tabular}{|c|c|c|}
\hline ESTUDO & CONTEXTO RESTRITO & SUJEITOS \\
\hline Ajayi (2017) & $\begin{array}{l}\text { - Fronteira rural dos EUA } \\
\text { com o México. } \\
\text { - San Diego State University, } \\
\text { Imperial Valley Campus }\end{array}$ & - 14 professores em formação inicial \\
\hline Borrero (2009) & $\begin{array}{l}\text { - Contexto urbano dos EUA } \\
\text { - Universidade de São } \\
\text { Francisco }\end{array}$ & $\begin{array}{l}\text { - Entre } 6 \text { a } 12 \text { professores em formação } \\
\text { inicial, de um Programa de Formação de } \\
\text { Professores para o Avanço de uma } \\
\text { Sociedade Multicultural (TEAMS) }\end{array}$ \\
\hline Boylan e Woolsey (2015) & $\begin{array}{l}\text { - Universidade na região } \\
\text { metropolitana da Inglaterra }\end{array}$ & $\begin{array}{l}\text { - } 4 \text { professores em formação inicial, } \\
\text { inscritos no módulo de um semestre no The } \\
\text { Pupil Experience of Learning Mathematics } \\
\text { (PELM) }\end{array}$ \\
\hline Convertino (2016) & - EUA & -25 professores em serviço \\
\hline Fontoura (2017) & - Rio de Janeiro, Brasil & $\begin{array}{l}\text { - Professores em formação inicial em } \\
\text { residência pedagógica }\end{array}$ \\
\hline Gibson e Parks (2014) & - EUA & - Professores em formação inicial \\
\hline Henning (2013) & - EUA & $\begin{array}{l}\text { - } 6 \text { professores de pós-graduação, } \\
\text { participantes do grupo colaborativo de } \\
\text { professores de estudos sociais pós-SJOTEP } \\
\text { (formação de professores orientados para a } \\
\text { justiça social) }\end{array}$ \\
\hline Montero (2015) & - Costa Rica & - Alunos de pós-graduação \\
\hline Storms (2013) & - EUA & - 10 professores em curso de pós-graduação \\
\hline $\begin{array}{l}\text { Tinkler, Hannah, Miller e } \\
\text { Tinkler (2015) }\end{array}$ & - EUA & - 37 professores em serviço \\
\hline
\end{tabular}

Fonte: Elaboração nossa.

Como podemos observar, a maioria dos estudos foram realizados nos EUA. Nesse contexto específico, os estudos apresentam maior apelo para a temática da diversidade e da questão racial. Um dos estudos relata a existência de tensão na formação de professores, por conta de o maior número de alunos/professores em formação ser branco, ou se identificar como tal, e pelo fato de o curso ter sido realizado por uma professora formadora que se identificava negra, a qual refletia sobre o seu papel dentro de contextos marcados por uma diversidade cultural e racial. 
É interessante ressaltar que a abordagem da FPJS, quando não faz parte de um projeto maior ou integrado à formação, pode ser percebida como uma ação pessoal, sendo desvalorizada e até rechaçada, aprofundando preconceitos. Isso nos faz pensar, talvez, sobre a importância de tratarmos também da desconstrução da temática da formação de professores para a justiça social como sendo necessária apenas a determinados grupos, ou seja, ela precisa ser tratada a partir da perspectiva global de suas implicações.

No geral, percebemos que as temáticas e os referenciais teóricos que apoiaram os cursos estão relacionados com contextos específicos e seus problemas, e os temas mais evidenciados são sobre a educação para a diversidade e a educação multicultural.

\section{Principais temas abordados e quadro teórico de apoio}

Todos os estudos referem-se ou tratam do tema geral, a FPJS. Entretanto, somado a este, aparecem outros temas e abordagens metodológicas de apoio, como, por exemplo, as pedagogias de caráter social e transformadoras, estando, dentre as citadas, as pedagogias da liberdade e da conscientização. Seguem, também, dentre os principais temas discutidos: diversidade, educação em direitos humanos, educação multicultural e inclusão.

Quadro - 8: Temas mais tratados nos estudos

\section{PRINCIPAIS TEMAS/TEORIAS CITADAS NOS ARTIGOS}

\begin{tabular}{|l|l|}
\hline 1. Pedagogia & $\begin{array}{l}\text { Pedagogia do desconforto, Pedagogia da investigação sobre a posição pessoal e sobre as } \\
\text { raízes sociais e econômicas da injustiça, Pedagogia da liberdade, Pedagogia da justiça } \\
\text { social, Pedagogia culturalmente relevante, Pedagogia da colaboração, Pedagogia da } \\
\text { resistência, Pedagogia da conscientização, Pedagogia de seminários etc. }\end{array}$ \\
\hline 2. Diversidade & $\begin{array}{l}\text { Diversidade dentro da escola, Educação multicultural em justiça social, Educação em } \\
\text { direitos humanos, Educação multicultural, Diversidade, democracia, inclusão justiça } \\
\text { social, Teoria da atividade cultural e histórica, Conscientização e receptividade dos } \\
\text { professores na preservação da diversidade }\end{array}$ \\
\hline 3. Contexto & $\begin{array}{l}\text { Treinamento em sala de aula, residência pedagógica, aprendizado de serviço nos } \\
\text { programas de preparação de professores }\end{array}$ \\
\hline
\end{tabular}

Fonte: Elaboração nossa.

Podemos inferir que a formação com abordagem na justiça social tem como princípio realizar-se em um determinado contexto. Alguns estudos descrevem a formação realizada na oportunidade de alunos matriculados em disciplinas práticas, em programas de residência pedagógica, no trabalho colaborativo com professores mais experientes e na sala de aula, como a formação em serviço, que foi o caso de estudos realizados em formação continuada, em nível de pós-graduação.

Além dos três principais temas tratados, também registramos conteúdos sobre: identidade, perspectiva crítica de educação, comunidades de pesquisa, letramento, currículo e modelos de 
engajamento comunitário, ou seja, todos esses temas podem estar relacionados à FPJS. No Quadro abaixo, situamos as principais referências teóricas que apoiaram as investigações e que podem constituir referencial teórico para a elaboração de formação de professores com foco na justiça social.

Quadro - 9: Principais referências que apoiaram os estudos

\begin{tabular}{|l|c|}
\hline \multicolumn{1}{|c|}{ ESTUDOS } & PRINCIPAIS AUTORES CITADOS \\
\hline Ajayi (2017) & \\
Convertino (2016) & \\
Borrero (2009) & 1. Marilyn Cochran-Smith \\
Boylan e Woolsey (2015) & \\
Henning (2013) & \\
Storms (2013) & \\
\hline Ajayi (2017) & \\
Convertino (2016) & 2. Paulo Freire \\
Fontoura (2017) & \\
Henning (2013) & \\
Montero (2015) & \\
Tinkler, Hannah, Miller e Tinkler (2015) & 3. Sonia Nieto \\
\hline Ajayi (2017) & \\
Convertino (2016) & \\
Borrero (2009) & \\
Boylan e Woolsey (2015) & \\
Gibson e Parks (2014) & \\
Henning (2013) & 4. Kenneth M. Zeichner \\
\hline Boylan e Woolsey (2015) & \\
Fontoura (2017) & 6. James Albert Banks \\
Henning (2013) & \\
Storms (2013) & \\
\hline Ajayi (2017) & \\
Convertino (2016) & \\
Henning (2013) & \\
\hline Ajayi (2017) & \\
Convertino (2016) & \\
Gibson e Parks (2014) & \\
\hline
\end{tabular}

Fonte: Elaboração nossa.

Marilyn Cochran-Smith, Paulo Freire e Sonia Nieto são os autores mais citados nos trabalhos analisados. Marilyn Cochran-Smith, pesquisadora norte-americana, traz para os estudos uma discussão sobre as comunidades de pesquisa e a prática e a política de formação de professores comprometidas com a justiça social. Paulo Freire, educador brasileiro, bastante conhecido a partir de suas obras sobre a pedagogia pautada na libertação, traz a ideia de resistência e de transformação social. Sonia Nieto, também pesquisadora norte-americana, traz os temas da diversidade, do multiculturalismo, da diversidade linguística, da equidade e da justiça social na educação.

$\mathrm{Na}$ sequência dos autores mais citados, temos Kenneth M. Zeichner, Henry Giroux e James Albert Banks. Kenneth M. Zeichner, pesquisador norte-americano, tem larga produção sobre formação 
de professores e justiça social. Henry Giroux encontra-se nos estudos por estar entre os principais teóricos da pedagogia crítica, assim como Paulo Freire. E James Albert Banks, educador norte-americano, é pioneiro na educação multicultural.

Os estudos realizados em formação inicial foram: Ajayi (2017), Borrero (2009), Boylan e Woolsey (2015), Convertino (2016), Fontoura (2017), Gibson e Parks (2014), Henning (2013) e Tinkler, Hannah, Miller e Tinkler (2015); e os estudos realizados em formação continuada, em nível de pósgraduação, foram: Montero (2015) e Storms (2013). Mas, todos os cursos de formação tiveram um momento comum dedicado ao estudo de literatura específica para sensibilizar os futuros professores aos princípios da justiça social, mas somente alguns optaram por combinar esse momento com o desafio de colocar os sujeitos participantes em situações prático-colaborativas. A seguir, sintetizaremos as estratégias didáticas utilizadas nos estudos.

\section{Natureza prática, estratégias formativas e conclusões}

Cada um dos estudos aqui analisados empregou, como estratégia didático-pedagógica, as seguintes estruturas: o formato, se teórico/reflexivo e/ou prático; a duração e as etapas, alguns estudos deixaram bem claras suas etapas, seus módulos e momentos diferentes bem definidos no texto; as atividades propostas; e os principais resultados e conclusões. Optamos por apresentar a síntese sobre os estudos em ordem alfabética.

Ajayi (2017) investigou as perspectivas dos professores sobre a formação e o ensino com base na abordagem da justiça social (JS) em escolas rurais, mostrando como foi implementado esse conceito em sala de aula e os desafios enfrentados. O curso teve a duração de 16 semanas, as quais foram organizadas da seguinte forma: Semana 1 - estudo do contexto; Semana 2 - discussão de estratégias para os participantes selecionarem e organizarem as técnicas instrucionais e as tarefas de aprendizagem; Semana 3 - discussão sobre como os professores poderiam usar os princípios da justiça social para influenciar o ensino; Semana 4 - discussão da avaliação da aprendizagem dos alunos; Semana 5 discussão de como analisar a eficácia do ensino e o que os docentes/participantes precisariam fazer de diferente; da $6^{a}$ à $14^{a}$ Semana - elaboração de um projeto de campo, planos de aula e lições nas escolas. Os formandos realizaram também um portfólio eletrônico, para expor seus planos de aula, comentários e reflexões através do TaskStream, um software baseado na web. Nas semanas 15 e 16, os participantes compartilharam um feedback em entrevistas de acompanhamento.

Ajayi (2017) conclui que a maioria dos alunos/participantes não aplicou os princípios da JS nas aulas e não fez a conexão entre os conhecimentos dos princípios da JS para a análise crítica contextual. Para obter resultados mais positivos, Ajayi (2017) considera que as formações podem: ser baseadas no contexto, nos problemas e no desafio a serem superados; levar experiências significativas às comunidades locais ou de contextos específicos; utilizar a estratégia de projetos comunitários baseados na pesquisa e 
na resolução de problemas; propor cursos de formação para entender os aspectos históricos e estruturais mais amplos da educação; promover diálogo e colaboração com outros professores que já promovem a FPJS; e continuar a usar os princípios de JS na formação de professores, para desafiar o modelo imposto que reproduz injustiças.

Borrero (2009) descreve, em seu estudo, a experiência de um programa de formação de professores em serviço, os quais buscaram apoio para suas práticas em sala de aula e colaboração com professores em formação inicial. Com a aposta na "comunidade de pesquisa" como um elemento-chave na formação docente, o estudo destacou a importância de novos professores embarcarem em suas carreiras com uma visão de JS. O desenvolvimento profissional, o trabalho em rede e o aprendizado em serviço são destacados pelo autor do estudo como positivos para o sucesso na formação dos docentes. Através de duas dinâmicas, o curso de formação consistiu em: pedagogia de seminários - os participantes assistiram, aos sábados, durante um ano letivo, das $10 \mathrm{~h}$ às $16 \mathrm{~h}$, aos seminários dinamizados por especialistas, sendo que, para cada sábado, foi estruturado um seminário pedagógico para tratar de um tema, seguido de workshops; e proposição de um tempo em "família" (grupos menores), para networking, questionamento e reflexão.

Os seminários específicos variavam sob o ponto de vista da temática, tratando de questões de raça, desenvolvimento curricular, avaliação e ensino culturalmente responsivo, para serem aplicados pelos professores em serviço e, posteriormente, em seus próprios contextos de ensino. O desafio era: “Como você vai tražer o tema justiça social para o seu currículo?” (BORRERO, 2009, p. 223 ). Depois dos seminários, foram realizadas oficinas para ajudar os participantes a desenvolverem estratégias específicas para a prática educativa em torno de alguns tópicos, como, por exemplo: conexão com as famílias dos alunos para ajudar na leitura, encontro com a justiça social no currículo roteirizado e como trazer a justiça social para a sua aula de ciências (BORRERO, 2009). Os grupos eram tipicamente compostos por 6 a 10 participantes, os quais compartilhavam uma especialidade de ensino, área de conhecimento ou série. Um professor com mais experiência atuava como líder do grupo e ajudava todos a refletirem sobre o conteúdo do dia. Cada participante tinha que projetar e implementar um projeto baseado em serviços prestados à comunidade.

Borrero (2009) conclui que é um grande desafio construir uma rede de colaboração necessária para uma boa formação de professores, visto que os alunos/docentes compartilham sentimento de alívio quando trabalham em redes de apoio. Uma visão de justiça social precisa ser fundamental para o desenvolvimento de um novo professor, e o compromisso com uma visão para um ensino bem-sucedido nas escolas urbanas promoverá a longevidade no ensino mais do que um foco apenas na prática.

Boylan e Woolsey (2015), por sua vez, usaram relatos socioculturais de identidade e enfatizaram aspectos indeterminados na construção da identidade profissional. O estudo desses autores, em formação inicial, representa uma contribuição empírica, teórica e metodológica que examina a relação entre identidade e envolvimento com questões de JS, na preparação de professores. Na sua sequência 
didática, primeiramente, os participantes do módulo “The Pupil Experience of Learning Mathematics" (PELM) (A Experiência do Aluno ao Aprender Matemática) foram encorajados a investigar os efeitos das práticas dominantes que levam às relações alienadas e alienantes com a matemática e que são experimentadas por aqueles que não são econômica ou culturalmente privilegiados. Em seguida, esses participantes vivenciaram uma pedagogia do desconforto, realizaram o exame crítico de influências históricas e atuais sobre políticas e práticas, estudaram diferentes pedagogias orientadas para a JS e compararam práticas realizadas em outros contextos. Questões de JS foram explicitamente abordadas em sessões específicas de ensino, e, como avaliação, os participantes tiveram que se concentrar nessas questões no seu trabalho avaliativo.

Boylan e Woolsey (2015) concluem que é importante tornar as preocupações filosóficas em um aspecto explícito nos currículos de formação de professores. Os discursos usados na educação também podem ser produtivamente objeto de reflexão crítica por professores iniciantes, em relação às questões de JS. Dar atenção aos aspectos dinâmicos da construção da identidade permitiu investigar como os sujeitos se posicionam em relação às questões de JS. Para os autores, a história de vida e a reflexão sobre a construção da identidade dos futuros professores são pontos de partida para a formação sensível diante das injustiças.

Convertino (2016) descreve o uso de um Modelo Crítico e Dialógico (MCD) para tratar de educação multicultural e justiça social no curso de formação com professores em serviço. Seu estudo baseou-se nas suas experiências de ensino como formador e destacou como as características-chave do MCD podem ser usadas para ajudar os professores a irem além na questão de pensar a educação multicultural como obstáculo étnico. A estratégia foi estruturar a interação dos participantes e criar conhecimento compartilhado. As discussões em sala, sobre o posicionamento diante de temas como raça e poder, criaram diálogos com base em diversas vozes, perspectivas e experiências diferentes. A partir da produção de diários, foram incluídas múltiplas perspectivas e a construção de significados compartilhados nas discussões em sala de aula, os alunos/participantes foram instruídos a escutar ativamente e a tentar fazer conexões entre os diários produzidos por eles e as leituras do curso. O objetivo com a expansão da conversa não era o de se chegar a um acordo, mas, sim, o de sustentar um diálogo crítico e reflexivo que os levasse a pensar em tópicos de maneiras novas e mais profundas.

Em uma segunda etapa, chamada de "Curso II", a estratégia foi a construção de uma bibliografia anotada, produzida durante um semestre e hospedada no site do curso on-line. Os participantes produziram anotações e questões semanais, que eram respondidas também semanalmente. Junto às experiências em sala de aula, os professores em serviço deveriam estabelecer bases para um projeto em grupo, cujo objetivo central era o de refletir sobre como a consciência de sua própria localização social moldava seus pontos de vista sobre a educação multicultural e a justiça social. Por conseguinte, eles foram obrigados a completar um questionário crítico de história de vida, baseado num conjunto de questões desenvolvidas para aprofundar a consciência crítica dos participantes. 
Convertino (2016) conclui que o MCD ajuda a compreensão mais profunda de: como a posição e a localização social dos indivíduos em uma sociedade estratificada moldam seus pontos de vista e suas perspectivas sobre as desigualdades sociais e educacionais; como o conhecimento é construído socialmente; e como ouvir e incorporar vozes diversas e perspectivas alternativas criam novas compreensões.

Fontoura (2017) aborda, em seu estudo, um processo de formação de professores dentro do programa de Residência Pedagógica, ressaltando que a formação reflexiva deve vincular-se à luta pela construção da justiça social. A formação aconteceu em reuniões mensais aos sábados, visando promover encontros e ouvir as falas sobre a inserção na docência, além de discutir dilemas e trocar experiências. Em todos os encontros, foi desenvolvido um trabalho individual sobre o tema "ser professor", através do relato oral, da representação gráfica, da escrita de si, ou mesmo a partir de depoimentos mais completos, relacionados com o tema do encontro, que se tornaram coletivos nas trocas entre os envolvidos.

Fontoura (2017) conclui que um processo reflexivo e atuante de diálogo entre pares pode reforçar as possibilidades de sucesso do espaço da Residência Pedagógica, como sendo uma das possibilidades para formarmos professores para a justiça social. O autor enfatiza a importância do diálogo como uma estratégia para enfrentar as situações de desigualdade social, através do trabalho pedagógico na construção de seres sociais com capacidade de falar, de escutar, de dialogar e de trabalhar em cooperação. Em outras palavras, a formação do docente com foco na superação de injustiças sociais necessita de diferentes abordagens metodológicas, as quais devem relacionar a construção da identidade profissional e sua postura crítica e reflexiva diante das injustiças sociais. Para o autor, tal relação merece maior espaço de discussão ao longo da formação de professores.

Gibson e Parks (2014) investigaram as dificuldades da formação de professores quando os alunos, participantes do estudo, são confrontados com o estabelecimento de um currículo de justiça social. Apoiados na literatura multicultural como ponto de partida para as conversas críticas que impulsionam as mudanças curriculares, os participantes falaram dos desafios presentes nas salas de aula de hoje, estando claramente desconfortáveis com o pensamento de fazer mudanças no currículo estabelecido.

Os participantes desse estudo foram expostos a diferentes lições, cada uma com um tema a ser explorado. Em atividades de "resposta de leitura", os leitores reagiam e respondiam à literatura estudada de diferentes maneiras, principalmente quando colocados a interpretar os textos através de sua própria história pessoal, seus conhecimentos e suas crenças. Também foram colocados aos participantes exemplos de ensino culturalmente sensível, com o objetivo de desafiar estereótipos. Os futuros professores aprenderam a selecionar materiais para leituras relevantes com as crianças que ensinarão, garantindo que elas reflitam a diversidade cultural. Além disso, os participantes da formação leram e 
escutaram pontos de vista variados sobre questões de poder e privilégio, censura, justiça social e sensibilidade às diferenças, e, no fim, desenvolveram produções escritas reflexivas.

Gibson e Parks (2014) concluem que três coisas são importantes: a conscientização sobre o reconhecimento da cultura em salas de aula, daí a importância da literatura cuidadosamente selecionada; o desafio de estabelecer um currículo de justiça social; e uma ampla gama de ferramentas para ajudar os futuros professores a orientarem, com sucesso, a aprendizagem dos alunos.

Henning (2013) apresenta um estudo com um grupo colaborativo de um programa de formação de professores para a justiça social. Durante um ano, o autor acompanhou seis professores em serviço, matriculados em um programa de pós-graduação em formação de professores, orientado para a justiça social. As práticas e os conceitos compartilhados pelos participantes do estudo foram desenvolvidos e levados para suas salas de aula e escolas, considerando o contexto e a colaboração. O curso ocorreu em 11 reuniões, nas quais os professores falavam de suas experiências e problemas, depois se reuniam para pensar em como resolvê-los. As atividades consistiam também em leituras e discussão de textos, oficinas, treinamentos sobre JS com outros professores colaboradores, seminário socrático (discussão centrada em um texto) e simulação histórica, em que os participantes tinham que pesquisar, analisar e retratar um famoso líder revolucionário e depois levar para suas aulas. Henning (2013) conclui que os programas e os pesquisadores devem defender e praticar uma abordagem mais coerente, crítica, integrada, baseada na investigação e orientada para a JS, no ensino e na formação de professores.

Montero (2015), em seu estudo, apresenta sua experiência pedagógica em nível de formação continuada com professores em serviço, para a promoção da JS. O autor defende que, através de uma mudança paradigmática, é possível resgatar a vocação emancipadora da prática educativa com os professores. O curso de formação dividiu-se em seis diferentes etapas: 1) observação de características comuns na sociedade de hoje, em que os participantes tinham que listar e analisar comportamentos e atitudes comuns nas pessoas de hoje, mesmo entre eles; 2) realização de um balanço do que a sociedade ganhou e perdeu em termos de humanização e harmonia com o meio ambiente, com um período de pesquisa e reflexão que se estendeu por um mês, em que os participantes organizaram informações e compartilharam suas ideias; 3) identificação de possíveis causas ou influências que levaram a efeitos positivos e negativos; 4) crise, indignação e protesto contra as forças que impedem a emancipação do ser humano e de seu meio ambiente; 5) avaliação dos esforços na educação para transformar realidades; 6) elaboração de propostas alternativas com base na realidade local dos alunos/participantes, projeção das atividades de classe e dos projetos de curso, para tratar de tolerância, participação e igualdade.

Montero (2015) diz que a JS só virá como resultado da luta tenaz para atender ao ideal da liberdade humana. Os adversários, nessa luta, serão as estratégias mercantilistas de suplantar o conteúdo pela imagem e de tornar atraente, desejável e até necessário o que poderia ser acessório, dispensável. E, para uma educação comprometida com a dimensão real da liberdade humana, em pesquisas futuras, será 
necessário focar na formação de professores, em relação ao binômio liberdade e justiça, e no desenvolvimento de trabalhos com populações estudantis de diferentes idades e contextos específicos.

Storms (2013) defendem que, para preparar os professores para se tornarem defensores da JS, é necessário que estes tenham a oportunidade de refletir criticamente sobre o currículo e sobre as estratégias de ensino, para perceberem como estão agindo em relação a temas como diversidade e justiça social. Em um curso baseado na pesquisa-ação, em nível de mestrado e de formação continuada, os autores optaram por uma abordagem crítica, buscando verificar o nível de prontidão para as ações em defesa da JS, em sala de aula. O curso durou 15 semanas, e as discussões em classe ocorreram em grupos pequenos, concentrando-se principalmente em leituras e processo de pesquisa. Os participantes praticaram técnicas de coleta e análise de dados e foram orientados por perguntas reflexivas para fazerem leituras e se prepararem para as discussões em grupo. Várias conferências foram ministradas no final das sessões de aula, para reiterar as informações importantes e abordar as questões levantadas durante as discussões em aula.

Storms (2013) argumentam que fundir a educação para a justiça social em um currículo de pesquisa-ação e incorporar a pedagogia de justiça social na sala de aula podem preparar os futuros professores para se tornarem seus defensores e alcançarem objetivos emancipatórios. O processo de envolvimento em pesquisa-ação, combinado com a comunidade de pesquisa-ação, contribuiu, de forma significativa, para a prontidão na defesa da JS. Os participantes afirmaram que o projeto de pesquisa-ação foi significativo e relevante para suas vidas, ajudando-os a refletir sobre suas práticas de ensino. Os futuros professores descreveram a comunidade da sala de aula como sendo participativa, colaborativa e solidária, além disso, para eles, a comunidade de aprendizado contribuiu para sua preparação em relação à defesa da JS.

Por fim, Tinkler, Hannah, Miller e Tinkler (2015) apresentaram uma experiência de campo com professores em serviço, em um curso para ajudar futuros professores no combate às injustiças institucionalmente "invisíveis" nas escolas públicas. Os participantes do curso examinaram os contextos das escolas onde trabalhavam, para identificar as estruturas institucionais que criavam desigualdades na educação. Segundo os autores, essa é uma boa experiência para a formação em serviço voltada para a JS. Dentro de um curso de Fundamentos Sociais e de um programa de tutoria, os participantes foram para as escolas e produziram documentos de reflexão ao longo do semestre, ademais escreveram artigos considerando suas experiências com seus tutores. No final do semestre, os professores escreveram uma reflexão mais extensa, fazendo uma análise global da experiência e explicando as conexões que fizeram entre o conteúdo do curso e a experiência da tutoria.

Tinkler, Hannah, Miller e Tinkler (2015) apresentaram três resultados principais da experiência: a necessidade de uma maior exposição à diversidade; a urgência de uma ênfase mais abrangente sobre os alunos como indivíduos; e a premência de uma visão mais ampla do contexto social das escolas. As descobertas demonstraram como a formação docente com base em conteúdos de JS pode 
ser usada para ajudar a reorientar os professores sobre uma maior atenção à diversidade e às necessidades individuais dos alunos em suas aulas, e para fazê-los entender e questionar as estruturas escolares existentes.

Em síntese, percebemos que a formação de professores para a justiça social apresenta muitos desafios, como, por exemplo, superar o trabalho isolado. A perspectiva de uma formação de professores para a justiça social deve ser um princípio e um fundamento dentro dos currículos de formação, independentemente se ela é inicial ou continuada ou se ela é para a educação básica ou superior. Possuímos problemas sociais que violam vidas, o que torna tal perspectiva de formação necessária em todos os níveis e ao longo da formação do docente, não podendo ser limitada à realização de cursos isolados.

Observamos que as formações docentes seguem alguns princípios básicos. Conduzir uma formação para a promoção da justiça social requer que esta seja de caráter culturalmente sensível, desenvolvida de forma colaborada e pertinente ao contexto em que ocorre. A literatura de base deve trazer para a sala de aula discussões sobre diversidade, multiculturalidade e currículo culturalmente responsivo. A formação de professores deve ser sensível ao contexto em que ocorre e os temas tratados devem partir dos problemas que as comunidades enfrentam. Observar o contexto é um princípio fundamental para a concepção de uma formação para a JS, ou seja, não há modelos ou fórmulas metodológicas, mas, sim, a complexidade do contexto, e é a partir dessa complexidade que as estratégias de formação são pensadas.

Um outro aspecto importante percebido nas formações de professores foi a meta da transformação, e, quando falamos em transformação, não falamos só do contexto, também falamos da transformação em um universo particular, micro, que acontece nos próprios sujeitos. Alguns dos cursos aqui explorados oportunizaram o momento particular de transformação de crenças pessoais dos docentes e da conexão de suas identidades profissionais com os princípios da JS. Isso implica que a formação deve ser sensível às subjetividades pertencentes ao grupo com o qual vamos trabalhar como formadores. E, para esse trabalho de transformação nos próprios sujeitos, observamos que os cursos tinham um apelo muito forte na construção do senso crítico dos participantes e, para que isso ocorresse, utilizaram algumas pedagogias com um caráter desafiador, social, crítico e reflexivo.

Além do Modelo Dialógico Crítico (MDC), dos modelos de engajamento comunitário e da pedagogia da conscientização, destacamos especialmente duas outras pedagogias que apoiaram alguns estudos e que nos parece interessante compreendê-las melhor: a "Pedagogia do desconforto" e a Teoria da Resistência Transformacional (TRT).

A Pedagogia do desconforto (BOLER, 1999; BOLER; ZEMBYLAS, 2003), utilizada no trabalho de Boylan e Woolsey (2015, p. 64), é uma pedagogia baseada no insistente questionamento sobre as crenças dos sujeitos em formação, como, por exemplo, colocar os pressupostos assumidos por aqueles que estão em situação privilegiada em confronto com as fontes de reprodução de injustiças, pois "uma 
maneira de gerar desconforto é através da investigação e, uma vez que as crenças são desconfortáveis, a investigação pode ser estimulada". A pedagogia do desconforto visa romper com crenças que impedem a compreensão de como o futuro professor deve desenvolver seu trabalho dentro dos princípios da promoção da justiça social.

A Teoria da Resistência Transformacional (BRAYBOY, 2005; COLLATOS, 2005; COVARRUBIAS; REVILLA, 2003; OTOYA-KNAPP, 2004; SOLÓRZANO; DELGADO BERNAL, 2001; TURNER, 2003; YASSO, 2000), citada no trabalho de Henning (2013), é baseada na resistência e na transformação da prática. Em seu estudo, o autor diz que:

A teoria da resistência transformacional (TRT) argumenta que as pessoas utilizam diferentes formas de resistência, variando de menos produtivas a mais produtivas. Para este estudo, a noção de resistência transformacional é essencial na maneira como aborda as questões que muitos novos educadores da justiça social levantam em suas próprias lutas individuais e coletivas. ${ }^{4}$ (HENNING, 2013, p. 124, tradução nossa).

As posturas e os comportamentos que incluem um desejo por JS e o combate a qualquer tipo de opressão são atitudes importantes a serem detectadas nas práticas de sala de aula e percebidas nas crenças dos professores em serviço ou em formação inicial. A metodologia da TRT é baseada na exposição do indivíduo a exemplos de resistências, como os movimentos sociais e os eventos históricos, com discussão de seus objetivos, de suas lutas e dos principais personagens envolvidos em movimentos de revolução e resistência. Os eventos de resistências podem ser trabalhados levando-se em consideração o próprio contexto em que o indivíduo está inserido e em dinâmicas que realizem simulação histórica, pesquisa, análise e representação de um famoso líder revolucionário, além de debates sobre esses eventos.

Percebemos, também, que falar sobre justiça social hoje parece algo óbvio, porém Gibson e Parks (2014, p. 43) argumentam:

Como educadores da justiça social e instrutores de cursos de literatura e educação multicultural, descobrimos resistência ao tentar ter conversas abertas e honestas em sala de aula, sobre livros que lidam com questões controversas, como raça, preconceito e privilégio. A resistência ocorre tanto na reação física quanto na emocional ao uso de palavras que muitos de nossos alunos foram ensinados a não usar. ${ }^{5}$ (Tradução nossa).

Ou seja, apesar de a justiça social ser uma temática aclamada, não é garantido que ela seja recebida de forma unânime e confortável. Por isso, é necessário insistirmos com o nosso trabalho, como educadores comprometidos com a justiça social, para fortalecer a luta contra todo tipo de opressão e fortalecer nossas práticas, sustentadas em objetivos de justiça e transformação social.

\footnotetext{
${ }^{4}$ Texto original: "Transformational resistance theory (TRT) argues that people utilize different forms of resistance, ranging from less productive to more productive. For this study, the notion of transformational resistance is essential in the way it addresses the issues that many new social justice educators raise in their own individual and collective struggles".

5 Texto original: "As social justice educators and instructors of literature courses and multicultural education, we discovered resistance when trying to have open, honest classroom conversations about books that deal with controversial issues such as race, prejudice and privilege. The resistance comes in both the physical and the emotional reaction to the use of words many of our students bave been taught not to use".
} 


\section{CONSIDERAÇÕES FINAIS}

Em nosso estudo, dedicamo-nos a conhecer mais profundamente as ações que vêm sendo realizadas dentro da formação de professores para a justiça social. Consideramos necessário acompanhar mais experiências e relatar as nossas próprias para que seja construída uma rede colaborativa de ações que insistam e resistam, com o objetivo de transformar realidades.

Como vimos, a interação de diferentes estratégias e o trabalho colaborativo marcaram os estudos analisados neste artigo. As formações docentes aconteceram no âmbito de cursos oferecidos por instituições de ensino superior e, em sua maioria, foram realizados por estudiosos que compartilharam suas próprias experiências como formadores, na oportunidade de seus cursos nas universidades. Isso significa que as instituições de ensino superior estão engajadas na formação comprometida com a transformação da sociedade, porém ainda precisam superar o trabalho isolado e insistir para que a formação de professores para a ajustiça social mantenha-se como tema constante, de interesse coletivo e efetivo nos programas de formação.

O estudo que realizamos nos ajudou a identificar um quadro teórico que pode subsidiar estudos futuros sobre a formação de professores para a justiça social, assim como nos ajudou a compreender os objetivos e as estratégias metodológicas mais empregadas e de maior sucesso. Além disso, ele fortalecerá as iniciativas dos estudos aqui analisados e de outros mais, incentivando o desenvolvimento de novos estudos e o envolvimento de mais pesquisadores na FPJS.

Os resultados das experiências apresentadas neste estudo auxiliaram-nos, também, a traçar um panorama do que ainda é necessário fazer e do que deve ser explorado para que as experiências formativas tenham mais sucesso. Mas, principalmente, ajudaram a identificar e reunir vozes em defesa de uma formação docente mais comprometida socialmente e da construção de um mundo mais justo através da educação.

Este estudo permitirá ainda melhorar a qualidade das formações oferecidas aos professores de língua portuguesa dentro dos princípios da justiça social, tema que vem sendo estudado pelas autoras deste trabalho. Os resultados aqui sintetizados são imprescindíveis para o desenvolvimento de um outro estudo em andamento, o qual, associado a resultados de outras investigações, pretende apresentar bases teóricas e apontar estratégias e tópicos que permitam articular a formação de professores de línguas para a justiça social. Nosso objetivo, com isso, é melhorar a qualidade dos currículos de formação inicial e continuada de professores de línguas e enfatizar o seu papel na transformação das sociedades e na promoção da justiça social, lacuna que é importante preencher no quadro da investigação em língua portuguesa. 


\section{REFERÊNCIAS}

AJAYI, L. Preservice Teachers' Perspectives on Their Preparation for Social Justice Teaching. The Educational Forum, v. 81, n. 1, p. 52-67, 2017. Disponível em:

https://doi.org/10.1080/00131725.2016.1242677. Acesso em: 20 mar. 2018.

BOLER, M. Feeling power: Emotions and education. New York: Routledge, 1999.

BOLER, M.; ZEMBYLAS. Discomforting truths: the emotional terrain of understandingdifference. In: TRIFONAS, P. (ed.). Pedagogies of difference: Rethinkingeducation for social change. New York:

Routledge Falmer, 2003. p. 110/136.

BOLIVAR, A. Justicia social y equidad escolar. Una revisión actual. Revista Internacional de Educación Para La Justicia Social (RIEJS), v.1, n. 1, p. 9-45, 2012.

BORRERO, N. Preparing New Teachers for Urban Teaching: Creating a Community Dedicated to Social Justice. Multicultural Perspectives, v. 11, n. 4, p. 221-226, dec. 2009. Disponível em: ttps://doi.org/10.1080/15210960903445723. Acesso em: 20 mar. 2018.

BOYLAN, M.; WOOLSEY, I. Teacher education for social justice: Mapping identity spaces. Teaching and Teacher Education, v. 46, p. 62-71, feb. 2015. Disponível em: https://doi.org/10.1016/j.tate.2014.10.007. Acesso em: 20 mar. 2018.

BRAYBOY, B. M. J. Transformational resistance and social justice: American Indians in Ivy League Universities. Anthropology \& Education Quarterly, v. 36, n. 3, p. 193/211, 2005.

COCHRAN-SMITH, M. Toward a Theory of Teacher Education for Social Justice. In: HARGREAVES, Andy; LIEBERMAN, Ann; FULLAN, Michael; HOPKINS, David (ed.). Second International Handbook of Educational Change. Springer International Handbooks of Education, v. 23. Springer Dordrecht Heidelberg London New York, 2010. p. 445-467. Disponível em: https://doi.org/10.1007/978-90-481-2660-6_27. Acesso em: 5 abr. 2018.

COCHRAN-SMITH, M.; ELL, F.; GRUDNOFF, L.; HAIGH, M.; HILL, M.; LUDLOW, L. Initial teacher education: What does it take to put equity at the center? Teaching and Teacher Education, v. 57, p. 67-78, jul. 2016. Disponível em: https://doi.org/10.1016/j.tate.2016.03.006. Acesso em: 5 abr. 2018.

COCHRAN-SMITH, M.; STRINGER KEEFE, E.; CARNEY, M. C. Teacher educators as reformers: competing agendas. European Journal of Teacher Education, v. 41, n. 5, p. 572-590, oct. 2018. Disponível em: https://doi.org/10.1080/02619768.2018.1523391. Acesso em: 5 abr. 2018a.

COLLATOS, A. M. Critical college access: Reframing how we empower urban youth toward higher education and social change. Unpublished doctoral dissertation. Los Angeles: University of California. 2005.

CONVERTINO, C. Beyond Ethnic Tidbits: Toward a Critical and Dialogical Model in Multicultural Social Justice Teacher Preparation. International Journal of Multicultural Education, v. 18, n. 2, p. 125-142, 2016.

COOK, D. J.; MULROW, C. D.; HAYNES, R. B. Systematic reviews: synthesis of best evidence for clinical decisions. Annalsof Internal Medicine., v. 126, n. 5, p. 376-380, 1997. 
COVARRUBIAS, A.; REVILLA, A. Agencies of transformational resistance. Florida Law Review, v. 55, n. 1, p. 459-477, 2003.

DINIZ-PEREIRA, J.; ZEICHNER, K. Justiça social: desafio para a formação de professores. Tradução de Cristina Antunes. Belo Horizonte: Autêntica Editora, 2008.

FONTOURA, H. A. da. Formação de Professores para a Justiça Social: uma reflexão sobre a docência na Residência Pedagógica. RLAEE - Revista Ibero-Americana de Estudos Em Educação, v. 12, n. 1, p. 120 133, 2017.

FREIRE, P. Pedagogia da autonomia: saberes necessários à prática educativa. São Paulo: Paz e Terra, 1997.

GIBSON, K..; PARKS, M. W. Toward Social Justice Literature to Promote Multiple Perspectives. Multicultural Education, v. 21, n. 2, p. 41-50, Winter 2014.

GIROUX, H. A escola crítica e a política cultural. Tradução de Dogmar M. L. Zibas. São Paulo: Cortez, 1992.

GIROUX, H. Os professores como intelectuais: rumo a uma pedagogia crítica da aprendizagem. Tradução de Daniel Bueno. Porto Alegre: Artes médicas, 1997. p. 157-163.

GIROUX, H.; MCLAREN, P. Formação do professor como uma contraesfera pública: a pedagogia radical como uma forma de política cultural. In: MOREIRA, A.; TADEU, T. Currículo, cultura e sociedade. 12. ed. São Paulo: Cortez, 2011.

HENNING, N. We make the road by walking together: New teachers and the collaborative and context-specific appropriation of shared social justice-oriented practices and concepts. Teaching and Teacher Education, v. 36, p. 121-131, nov. 2013. Disponível em: https://doi.org/10.1016/j.tate.2013.07.014. Acesso em: 26 de março de 2018.

MONTERO, L. G. B. Formación de nuevos docentes y educación continua para docentes en servicio: su aporte a la justicia social. Letras 57, n. 1, p. 179-194, 2015. (ISSN 1409-424X; EISSN 2215-4094).

MOREIRA, M.; ZEICHNER, K. Filhos de um deus menor. diversidade linguística e justiça social na formação de professores. Portugal: Edições Pedago, 2014.

OTOYA-KNAPP, K. When Central City High School students speak: doing critical inquiry for democracy. Urban Education, v. 39, n. 2, p. 149-171, 2004.

PARASKEVA, J.; GANDIN, L.; HYPÓLITO, A. Diálogos educacionais e curriculares à esquerda. Lisboa: Plátano Editora, 2005.

SÁ-CHAVES, I. Educar, Investigar e Formar: novos saberes. Aveiro, Portugal: Universidadee de Aveiro, 2014.

SAMPAIO, R. F.; MANCINI, M. C. Estudos de revisão sistemática: um guia para síntese criteriosa da evidência científica. Revista Brasileira de Fisioterapia, São Carlos, v. 11, n. 1, p. 83-89, jan./ fev. 2007. Disponível em: http://www.scielo.br/pdf/rbfis/v11n1/12.pdf. Acesso em: 5 abr. 2018.

SOLÓRZANO, D.; DELGADO BERNAL, D. Examining transformational resistance through a critical race and LatCrit theory framework: Chicana and Chicano students in an urban context. Urban Education, v. 36, n. 3, p. 308-342, 2001. 
STORMS, S. B. Preparing Teachers for Social Justice Advocacy Am I Walking My Talk? Multicultural Education, v. 20, n. 2, p. 33-39, 2013. Disponível em: http:// files.eric.ed.gov/fulltext/EJ1015111.pdf. Acesso em: 4 nov. 2018.

TINKLER, B.; HANNAH, L.; MILLER, E.; TINKLER, A. The impact of a social justice servicelearning field experience in a social foundation course. Critical Questions in Education, v. 6, n. 1, p. 16-29, 2015.

TURNER, E. E. Critical mathematical agency: Urban middle school students engage in mathematics to investigate, critique and act upon their world. Unpublished doctoral dissertation. University of Texas at Austin, 2003.

YASSO, T. A critical race and LatCrit approach to media literacy: Chicana/o resistance to visual microaggressions. Unpublished doctoral dissertation. Los Angeles: University of California, 2000.

ZEICHNER, K. Teacher education and the struggle for social justice. New York and London: Routledge, 2009.

ZEICHNER, K. Formação de professores para a justiça social. In: MOREIRA, M. A.; ZEICHNER, K. Filhos de um deus menor. diversidade linguística e justiça social na formação de professores. Portugal: Edições Pedago, 2014. p. 135-151.

ZEICHNER, K. Advancing Social Justice and Democracy in Teacher Education: Teacher Preparation 1.0, 2.0, and 3.0. Kappa Delta Pi Record, v. 52, n. 4, p. 150-155, sep. 2016. Disponível em: https://doi.org/10.1080/00228958.2016.1223986. Acesso em: 20 jul. 2018.

ZEICHNER, K. M.; DINIZ-PEREIRA, J. E. Pesquisa dos educadores e formação docente voltada para a transformação social. Cadernos de Pesquisa, São Paulo, v. 35, n. 125, p. 63-80, maio/ago. 2005. Disponível em: https://doi.org/10.1590/S0100-15742005000200005. Acesso em: 20 jul. 2018.

Submetido: $07 / 05 / 2019$

Aprovado: 27/10/2019 